\section{Endoscopic ultrasound-guided fine-needle aspira- tion can lead to nonresectability of pancreatic cancer due to severe biopsy-induced inflammation}

A 62-year-old man with a pancreatic mass was referred for endoscopic ultrasound (EUS), which demonstrated infiltration of the portal vein ( $\bullet$ Fig. 1). EUSguided fine-needle aspiration (FNA) was performed, with no signs of EUS-FNArelated complications. Cytological examination showed only suspicious cells. A second EUS-FNA performed 2 weeks later surprisingly revealed massive inflammation in and around the pancreas (๑ Fig. 2). FNA and cytology showed adenocarcinoma and the patient underwent downstaging with combined chemoradiotherapy. After chemoradiotherapy a third EUS examination showed no infiltration of the portal vein. The patient underwent laparoscopy with laparoscopic ultrasound, but resection proved impossible because of the massive inflammatory changes that had been observed on endosonography.

EUS-FNA is being used increasingly in the diagnosis and staging of pancreatic tumors, and it is considered to be an accurate and safe procedure [1-3]. Cases of acute pancreatitis following EUS-FNA have been described, but severe cases are rare [3]. There are no previous reports of surgery having to be abandoned as a result of inflammation caused by EUS-FNA, but prolonged surgical procedures due to inflammation caused by percutaneous biopsy of the pancreas has been described [4].

The inflammation seen in this case might have been caused by the preoperative therapy, but in our experience with more than 50 patients who were evaluated after receiving chemoradiotherapy we have not seen any patient with a nonresectable tumor due to inflammation. In addition, the inflammation had already been observed before the chemoradiotherapy was initiated.

In order to evaluate whether the present case was a one-off experience, we reviewed 26 consecutive patients with a

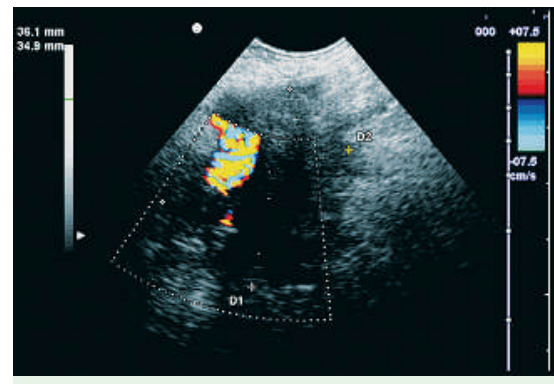

Fig. 1 Endoscopic ultrasound (EUS) image before the EUS-guided fine-needle aspiration (EUS-FNA) showing a 35-mm, echo-poor tumor infiltrating the portal vein.

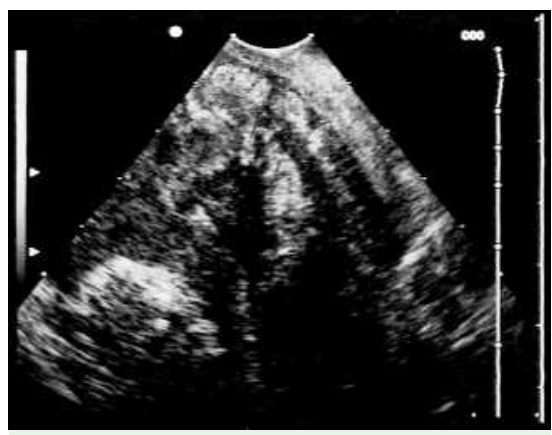

Fig. 2 EUS 2 weeks after the original EUS-FNA showed diffuse enlargement and an irregular echo pattern covering all of the pancreatic head region. The tumor cannot be differentiated from the inflammation.

nonresectable tumor who underwent downstaging. EUS-FNA was performed in 12 patients. In one of these patients inflammation resulted in prolonged surgery. Pathological examination of the specimen revealed massive fibrosis in and around the pancreas.

We conclude that although EUS-FNA is a safe diagnostic and staging procedure in patients with pancreatic cancer, it is associated with a risk of severe inflammation that can compromise the performance of potentially curative surgery.

Endoscopy_UCTN_Code_CPL_1AL_2AD

\section{S. Dahl, M. B. Mortensen}

Center for Surgical Ultrasound, Department of Surgical Gastroenterology, Odense University Hospital, Odense,

Denmark

\section{References}

1 Eloubeidi MA, Chen VK, Eltoum IA et al. Endoscopic ultrasound-guided fine needle aspiration biopsy of patients with suspected pancreatic cancer: diagnostic accuracy and acute and 30-day complications. Am J Gastroenterol 2003; 98: 2663-2668

2 Mortensen MB, Fristrup C, Holm FS et al. Prospective evaluation of patient tolerability, satisfaction with patient information, and complications in endoscopic ultrasonography. Endoscopy 2005; 37: 146- 153

3 Eloubeidi MA, Gress FG, Savides TJ et al. Acute pancreatitis after EUS-guided FNA of solid pancreatic masses: a pooled analysis from EUS centers in the United States. Gastrointest Endosc 2004; 60: 385-389

4 Mueller PR, Miketic LM, Simeone JF et al. Severe acute pancreatitis after percutaneous biopsy of the pancreas. AJR Am J Roentgenol 1988; 151: $493-494$

Bibliography

DOI 10.1055/s-2007-966607

Endoscopy 2008; 40: E96

(c) Georg Thieme Verlag KG Stuttgart · New York . ISSN 0013-726X

\section{Corresponding author}

\section{S. Dahl, MD}

Center for Surgical Ultrasound

Department of Surgical Gastroenterology

Odense University Hospital

Sdr. Boulevard 29

5000 Odense $C$

Denmark

Fax: +45-66113333

sdahl@dahl.mail.dk 